\title{
ATIVIDADE DE EXTENSÃO: ESTRATÉGIA PARA O INTERCÂMBIO DE CONHECIMENTO ENTRE OS ALUNOS DE ENFERMAGEM
}

\author{
Extension Activity: Strategy of Knowledge Interchange \\ among Nursing Students \\ Actividad de Extensión: Estrategia para el Intercambio del \\ Conocimiento entre los Alumnos de Enfermería
}

Norma Valéria Dantas de Oliveira Souza

Maristela Freitas Silva

Luciana Ranauro Assumpção

Keila Suellen Moura Nunes

Fabiana Maia Morgado

\begin{abstract}
Resumo
Estudo qualitativo, descritivo, tipo estudo de caso, cujo objeto foi o intercâmbio de conhecimento teórico-prático estabelecido entre os bolsistas do projeto de extensão denominado "Orientando o cliente em situação cirúrgica para diferenciar o cuidado" e os internos de Enfermagem que estagiam nos cenários das enfermarias cirúrgicas do Hospital Universitário Pedro Ernesto. Objetivos: identificar e analisar as situações e modos de ensino-aprendizagem nas quais se estabelecem intercâmbios de conhecimento teórico-prático entre internos e bolsistas e discutir a importância do projeto de extensão como uma estratégia para aquisição de conhecimento teórico-prático. Aplicouse uma entrevista semi-estruturada a quinze internos, e, após a análise de conteúdo, verificou-se que existiu intercâmbio de conhecimento quando da realização de grupos de orientação para clientes no pré-operatório, nas orientações individuais para o autocuidado no domicílio e através do material instrucional fornecido à clientela. Além disso, verificou-se que a atividade de extensão é uma importante estratégia que favorece o ensino-aprendizagem.
\end{abstract}

Palavras-chave: Enfermagem. Estudantes de Enfermagem. Educação em Enfermagem. Extensão Comunitária.

\begin{abstract}
Qualitative, descriptive study, such as case study, that has the object of interchanging theory-practical knowledge established among the extension project practicant students called "Guiding the client in surgical situation in order to distinguish the care" and nursing practicants that act in surgical nurseries scenes at Pedro Ernesto University Hospital (Rio de Janeiro - Brazil). Objective: To identify and analyse the situation and ways of teaching-learning in which it is possible to establish theory-practical knowledge interchange among practicants and interns and to discuss the importance of extension project as an strategy to acquire theory-practical knowledge. It has been applied a semi-structured interview to 15 interns and after content analysis, it has been verified that there was knowledge interchange when groups of orientation to pre-operatory clients has been made, at individual orientation for home self care and through instrument material given to the clients. Besides, it has been verified that extension activities are an important strategy that facilitates the teachinglearning process.
\end{abstract}

Keywords: Nursing. Studentes, Nursing. Education, Nursing. Community - Institutional Relations.

\section{Resumen}

Estudio cualitativo, descriptivo, del tipo estudio de caso, cuyo objeto fué el intercambio de conocimiento teóricopractico establecido entre los alumnos del proyecto de extensión llamado "Orientando el cliente en situación quirúrgica para distinguir el cuidado" y los internos de enfermería que practican en los escenarios de las Enfermarías Quirúrgicas del Hospital Universitario Pedro Ernesto (Rio de Janeiro - Brasil). Objetivo: identificar y analizar las situaciones y modos de enseñanza-aprendizaje, en las cuales se establecen intercambios de conocimiento teórico-práctico entre internos y practicantes y debatir la importancia del proyecto de extensión como una estrategia para adquisición de conocimiento teórico-práctico. Fue utilizada entrevista semiestructurada en quince internos y después del análisis de contenido se ha verificado que existió intercambio de conocimiento cuando se realizaron grupos de orientación para clientes en el préoperatorio en las orientaciones individuales para el auto cuidado en su casa y a través del material de instrucción fornecido a los clientes. Además, se ha verificado que la actividad de extensión es una importante estrategia que facilita la enseñanza-aprendizaje.

Palabras clave: Enfermería. Estudiantes de Enfermería. Educación en Enfermería. Relaciones Comunidad - Institución. 


\section{CONSIDERAÇÕES INICIAIS}

0 objeto deste estudo é o intercâmbio de conhecimento teórico-prático estabelecido entre os bolsistas do projeto de extensão denominado "Orientando o cliente em situação cirúrgica para diferenciar o cuidado" e os internos de enfermagem ${ }^{\mathrm{a}}$ que estagiam nos cenários das enfermarias de cirurgia geral do Hospital Universitário Pedro Ernesto (HUPE).

Um projeto de extensão caracteriza-se por ser um conjunto de atividades temporárias de caráter educativo, cultural, artístico e/ou científico, desenvolvido por docentes e discentes através de ações voltadas para questões sociais relevantes. Deve estabelecer uma troca integrada entre conhecimento acadêmico e popular, possibilitando ações que estimulem 0 desenvolvimento social. Deve propiciar nos estudantes uma conduta e uma formação crítica e reflexiva, contribuindo também para uma reflexão crítica das práticas curriculares e das linhas de pesquisa. 0 projeto de extensão auxilia na troca de saber e de experiência entre a comunidade e o público externo'.

0 Internato de Enfermagem é uma modalidade de ensino realizada através do treinamento em campos de prática, no hospital, unidades de saúde e comunidades, que atendam às peculiaridades das Áreas e Subáreas do Currículo da Faculdade de Enfermagem da Universidade do Estado do Rio de Janeiro (FENF/UERJ) voltado para a aprendizagem dos alunos do $8^{\circ} \mathrm{e}$ $9^{\circ}$ períodos. A carga horária do Internato compreende 2.160 (duas mil e cento e sessenta) horas distribuídas equitativamente entre os dois períodos mencionados. Tem como objetivo a capacitação dos alunos para planejar, executar, supervisionar e avaliar as assistências de enfermagem, desenvolver as atividades de educação e de pesquisa em comunidades, unidades da Rede Básica e hospitalar.

As enfermarias de cirurgia geral do HUPE são campos de estágios dos internos do $9^{\circ}$ período, especificamente as enfermarias $1 / 2$ e $4 / 5$, que atendem clientes em situação de pré e de pós-operatórios. Dentre as competências que eles devem atingir, destaca-se a capacidade de fornecer orientações que preparem bio, psico e socialmente os clientes para viver a experiência cirúrgica com o mínimo de estresse e para que saibam cuidar-se nos seus domicílios, após a alta hospitalar, evitando e/ou detectando precocemente complicações no pósoperatório mediatas e tardias.

Para adquirirem essa competência, os internos precisam conhecer e aplicar alguns instrumentos de enfermagem como: a observação, a comunicação, princípio científico, o planejamento, a avaliação, o trabalho em equipe, o método científico e o próprio processo cuidativo ${ }^{2}$. Quando empregam esses instrumentos ao prestar um cuidado de qualidade, fica evidente que as orientações fornecidas são incorporadas nos hábitos da clientela, e, dessa forma, constata-se que os medos, temores, ansiedades, enfim, sentimentos desagradáveis estreitamente vinculados à experiência cirúrgica, são desconstruídos ou pelo menos minimizados ${ }^{3}$.

Buscando desenvolver estratégias de ensino-aprendizagem que propiciem o desenvolvimento e fixação da competência anteriormente mencionada e, por conseguinte, contribuir para a melhora do padrão da assistência de enfermagem, implementou-se em março de 2005 o projeto de extensão intitulado "Orientando o Cliente em Situação Cirúrgica para Diferenciar o Cuidado". Esse projeto tem como objetivos: orientar clientes e familiares sobre a doença, o procedimento anestésico-cirúrgico e os cuidados perioperatórios; e contribuir para minimizar complicações biopsíquicas e sociais nos clientes em pós-operatório.

Durante o ano de 2005 e início de 2006, o projeto contemplou quatro bolsistas, uma do $5^{\circ}$ período, duas do $6^{\circ} \mathrm{e}$ uma bolsista do $7^{\circ}$ período. Vale informar que os alunos do Internato não podem ser recrutados para receber a bolsa de extensão devido à necessidade de dedicação exclusiva ao Internato e porque também já recebem outro tipo de ajuda financeira para cursarem o $8^{\circ}$ e $09^{\circ}$ períodos.

Os alunos do internato, por se encontrarem no final do curso de graduação, dispunham de maior habilidade psicomotora e domínio mais amplo da dinâmica de trabalho nas enfermarias. No entanto, apresentavam certa defasagem no conhecimento e habilidades de enfermagem no contexto cirúrgico, isto é, no atendimento às peculiaridades e necessidades da clientela em situação de cirurgia.

As bolsistas do projeto de extensão que estavam em períodos anteriores, por já terem sido capacitadas para compreender toda problemática de saúde dos clientes em situação cirúrgica, detinham conhecimento teórico mais aprofundado sobre os procedimentos anestésico-cirúrgicos, sobre os cuidados de perioperatório e sobre as possíveis complicações e riscos que a clientela estaria susceptível, sobretudo pelo tipo de cirurgia e pelo estado de saúde em que se encontravam. Elas também possuíam maior habilidade para orientar os clientes acerca dos cuidados de pré e pós-operatório e dos cuidados no domicílio. Porém, verificou-se certa insegurança durante a execução de alguns procedimentos de enfermagem, ou quando solicitadas para participarem da dinâmica do trabalho assistencial.

Apesar desse déficit circunstancial no processo ensinoaprendizagem das bolsistas e dos internos de Enfermagem, observou-se, aleatoriamente, que ambos os grupos desenvolveram uma integração peculiar em que ficou evidente o intercâmbio de conhecimento teórico-prático, no qual quem detinha maior conhecimento ensinava aquele que não o possuía.

Segundo Almeida e Souza ${ }^{4}$, há urgente necessidade de pensar estratégias de ensino-aprendizagem que integrem conhecimento teórico-prático e também integrem docentes e discentes num esforço conjunto para construção e consolidação do conhecimento da Enfermagem para a melhoria dos cuidados prestados. Assim, o ensino deve determinar:

A busca por uma formação profissional que permita ao futuro enfermeiro ter uma postura crítica, política, preparado para atuar de modo criativo e inovador é um desafio [...]. Elaborar formas de ensinar e aprender que tenham como eixo direcionador à construção conjunta do conhecimento teórico-prático, em que discentes e docentes sejam agentes ativos do processo ensinoaprendizagem, é uma meta que precisa ser atingida a:208. 
A partir dessa observação inicial, decidiu-se elaborar a pesquisa em tela, a qual foi guiada pelas seguintes questões norteadoras:

- Existe intercâmbio de conhecimento teórico-prático entre os internos de Enfermagem e as bolsistas do projeto de extensão?

- Quais são as situações e modos que permitem o intercâmbio de conhecimento teórico-prático entre as bolsistas e os internos?

- Qual é a importância do projeto de extensão como forma de viabilização do processo ensinoaprendizagem dos discentes de Enfermagem e de intercâmbio de conhecimento entre eles?

Traçaram-se três objetivos para a pesquisa: identificar situações e modos de ensino-aprendizagem nas quais se estabelecem intercâmbios de conhecimento teórico-prático entre internos e bolsistas; analisar as situações e os modos de ensino-aprendizagem estabelecidos entre internos e bolsistas; e discutir a importância do projeto de extensão como uma estratégia para aquisição de conhecimento teórico-prático.

\section{METODOLOGIA}

Optou-se por desenvolver um estudo qualitativo, descritivo, tipo estudo de caso. Lüdke e André ${ }^{5}$ salientam que a pesquisa qualitativa ilumina o dinamismo interno das situações, propiciando o conhecimento de como um problema se manifesta nas atividades, nos procedimentos e nas interações cotidianas. Permite ainda conhecer o que pensam os indivíduos sobre suas experiências, suas vidas e seus projetos, privilegiando o conteúdo da percepção e do individual.

A pesquisa descritiva ajuda a compreender a realidade estudada, pois, de acordo com Triviños ${ }^{6}$, a descrição tem por objetivo aprofundar determinada realidade, descrevendo com exatidão os fatos e fenômenos do que se deseja investigar. 0 estudo de caso é uma modalidade de pesquisa que visa a investigar fatos e fenômenos de uma determinada realidade, aprofundando-se na realidade em questão e sem a pretensão de buscar generalizações ${ }^{6}$.

0 cenário para o desenvolvimento da pesquisa foi o Hospital Universitário Pedro Ernesto situado no Município do Rio de Janeiro. Os sujeitos do estudo foram internos de enfermagem que já haviam estagiado nas enfermarias de cirurgia geral. Adotou-se também o critério da disponibilidade e do desejo de querer participar da pesquisa.

Após contato inicial com os sujeitos, explanação dos objetivos da pesquisa e assinatura do Termo de Consentimento Livre e Esclarecido, realizaram-se quinze entrevistas. De acordo com Fortes ${ }^{7}$, o Termo de Consentimento deve ser livre, esclarecido, renovável e revogável. Livre de restrições internas, causadas por distúrbios psicológicos e externos, por pressões de familiares, amigos e principalmente dos profissionais de saúde. Esclarecido, com adequadas informações que sejam compreendidas pelos sujeitos da pesquisa. Renovado, quando ocorrerem significativas modificações no panorama do caso, que se diferencia do momento e das circunstâncias nos quais foi obtido o consentimento inicial. E revogável, com 0 consentimento mutável, modificável a qualquer instante, por decisão livre e esclarecida, sem que ao sujeito sejam imputadas sanções morais ou administrativas.

0 instrumento de coleta das informações foi a entrevista semi-estruturada, aplicada nos meses de janeiro e fevereiro de 2006. 0 conteúdo das entrevistas foi gravado em fitas magnéticas e transcritas logo após a realização das mesmas.

Decidiu-se trabalhar com a entrevista semi-estruturada porque ela permite:

Certos questionamentos básicos, apoiados em teorias e hipóteses, que interessam à pesquisa e que, em seguida, oferecem amplo campo de interrogativas, fruto de novas hipóteses que vão surgindo à medida que se recebem as respostas do informante. Desta maneira, 0 informante, seguindo espontaneamente a linha de seu pensamento e de suas experiências, dentro do foco principal colocado pelo investigador, começa a participar na elaboração do conteúdo da pesquisa ${ }^{6: 146}$.

As informações coletadas foram tratadas à luz da análise de conteúdo ${ }^{8}$, o que possibilitou, então, a identificação de três categorias: o intercâmbio do conhecimento entre acadêmicos e internos de enfermagem; modos de intercâmbio do conhecimento entre acadêmicos e internos; e a importância do projeto de extensão para o processo ensino-aprendizagem.

Informa-se que foram seguidas todas as determinações da Resolução 196/96 do Conselho Nacional de Saúde/ MS, que regulamenta as pesquisa com seres humanos. Assim, a pesquisa foi apreciada pelo Comitê de Ética em Pesquisa (CEP) do Hospital Universitário Pedro Ernesto em junho de 2005, obtendo parecer positivo, liberando o desenvolvimento da pesquisa.

Para manter 0 anonimato, preservando a privacidade dos sujeitos da pesquisa, utilizou-se uma codificação, objetivando impedir qualquer tipo de ligação entre o conteúdo das entrevistas e os sujeitos. Assim, à medida que eram transcritas as entrevistas, elas recebiam o código de E1, E2 e assim sucessivamente, obedecendo a uma ordem cronológica de realização das transcrições.

\section{ANÁLISE DAS INFORMAÇÕES COLETADAS}

\section{1a Categoria: 0 intercâmbio do conhecimento entre acadêmicose internos de Enfermagem}

A análise das entrevistas revelou que houve um intercâmbio positivo de conhecimento entre os bolsistas e os internos de enfermagem, possibilitando o incremento das informações e dos conteúdos no contexto cirúrgico, favorecendo a socialização do conhecimento e a construção de laços afetivos entre internos e bolsistas. Verificou-se também o estabelecimento de relação de confiança, de admiração mútua e de segurança entre ambos os grupos. Os relatos a seguir revelam o exposto:

Então, com as bolsistas, a gente aprende como fornecer as orientações para o cuidado no pósoperatório e no domicílio. E12 
Durante o estágio, quando foi apresentada a clínica cirúrgica, os tipos de orientações do pré e do pósoperatório, houve uma integração, houve uma construção conjunta de conhecimento entre os dois grupos. Principalmente pelas orientações que as bolsistas passavam e que a gente ouvia e relembrava, e isso transmitiu uma sensação de segurança. E4

Foi bom porque teve interação, a gente teve oportunidade de conhecer as bolsistas um pouco melhor, porque a gente acaba ficando naquela de corredor, porque nós não somos da mesma turma; pudemos conhecer o potencial delas, que é muito grande e conhecemos um pouco mais das orientações, e vimos que tem que ter uma sensibilidade para abordar, para falar com o cliente, para chegar até ele e passar as informações necessárias. E7

0 processo ensino-aprendizagem na Enfermagem exige sensibilidade, intuição, criatividade, afetividade, conhecimento teórico-prático a fim de que as competências esperadas para um enfermeiro crítico-reflexivo e com potencialidades para transformar realidades obsoletas possam ser atingidas. Assim, constata-se que um meio eficaz de conquistar este perfil profissional é inovando as estratégias de ensino e envolvendo vários sujeitos neste processo, tornando-os co-participantes da dinâmica do ensinar e do aprender. Segundo Camacho e Espírito Santo ${ }^{10}$, a arte de cuidar e ensinar em enfermagem vai além das fundamentações teóricas, exigindo momentos em que somente o contato com o novo pode permitir e em que a oportunidade de troca entre as pessoas é fundamental. Mostardeiro ${ }^{11: 91}$, em seu estudo que buscou refletir sobre a formação profissional do enfermeiro a partir da prática docente, infere que:

É necessário que professores e alunos participem da criação e recriação da práxis de enfermagem, como integrantes de uma sociedade instituída e interagindo frente à necessidade de mudança e implementação do novo, socializando-se, incorporando valores, condutas que fazem parte do momento histórico-social no qual estão inseridos. 0 indivíduo tem a possibilidade de modificar o imaginário instituído através da motivação e de sua capacidade de criar, demandando assim uma revolução das práticas pedagógicas. 0 intercâmbio de conhecimento teórico-prático entre internos e bolsistas foi estabelecido, trazendo resultados profícuos para o processo ensino-aprendizagem. Essa troca foi viabilizada pela utilização de uma estratégia ainda pouco explorada na educação, as atividades extensionistas. Elaborar projetos de extensão com um olhar igualmente voltado para a clientela assistida e também para o processo pedagógico resulta num ganho maior para as partes envolvidas: ensino, assistência e comunidade.

\section{2a Categoria: Modos de intercâmbio do conhecimento entre acadêmicos e internos}

Houve variados modos e situações em que ocorreu 0 intercâmbio de conhecimento entre acadêmicos e internos de enfermagem, destacando-se os momentos de orientação individual dos clientes, preparando-os para o cuidado no domicílio; quando das orientações nos grupos dos clientes em período pré-operatório, aproximando-os do cuidado hospitalar; quando da elaboração e leitura do material didático-instrucional fornecidos à clientela e durante a execução de procedimentos específicos do contexto cirúrgico. As falas destacadas a seguir exemplificam o exposto:

Eu acho que foi durante um bate-papo (grupo de orientação) visando orientar os clientes, onde nós participamos também e aprendemos coisas legais. As bolsistas com o projeto levam todo conhecimento, toda a metodologia de ensino. E6

Eu nunca tinha visto um cliente ostomizado, eu não sabia os cuidados. No caso, as bolsistas têm experiência, já tiveram contato, já tiveram esta interação, ai eu aprendi com elas. E10

Muito do que eu aprendi foi lendo o material, entendeu? Aquela apostila, os fôlderes, o álbum seriado... E8

Quando o intercâmbio do conhecimento se estabeleceu no sentido dos internos de enfermagem para as bolsistas do projeto, ou seja, os internos ensinando as acadêmicas, verificouse que as situações de aprendizagem envolviam a rotina hospitalar, a dinâmica do trabalho na enfermaria, esclarecimentos acerca de como fazer alguns procedimentos de enfermagem ou mesmo o acompanhamento das bolsistas para a realização de procedimentos. Através das falas selecionadas, pode-se evidenciar esta análise.

Eu me lembro que eu ajudei a aluna (bolsista) a fazer uma punção de veia, a professora perguntou se ela queria fazer, ela disse que sim, mas depois pediu para eu ir com ela. Senti que ela estava insegura. E15

Ah! Elas não sabem muito para onde encaminhar um parecer, como registrar a alta do paciente e nós já sabemos, ai a gente fala para elas, orienta. E2

Identificaram-se as situações e os modos de intercâmbio do conhecimento estabelecido nas enfermarias cirúrgicas, decorrente das atividades de extensão, apontando para o fato de que os projetos de extensão desenvolvidos em locais onde acontecem os estágios supervisionados caracterizam-se em mais uma estratégia positiva para viabilizar o processo de aquisição e consolidação do conhecimento.

\section{3a Categoria: A importância do projeto de extensão para o processo ensino-aprendizagem no contexto cirúrgico}

A partir da análise das falas dos sujeitos investigados, verificou-se que eles valorizam a atividade de extensão proposta para o campo de estágio de enfermagem cirúrgica, pois esta atividade integra os alunos de vários períodos, consolida 0 conhecimento trabalhado em sala de aula, auxilia na apreensão de novos conhecimentos teórico-práticos e possibilita a aplicação do conhecimento teórico com a prática profissional. Através das falas selecionadas a seguir, é possível confirmar esta análise.

Eu acho que o projeto é importante porque integra o aluno da graduação com os alunos do internato num 
trabalho de esclarecimento, de educação para a saúde. Eu acho que os dois alunos têm muito a complementar um para o outro. 0 aluno do internato que já está terminando a faculdade e o aluno novo que está vindo com novas idéias, novos projetos. E1

Ele é importante, pois traz um conteúdo que não é muito frisado na faculdade, um conteúdo que a gente vê na prática que é importante, as orientações para o pré-operatório e para o pós-operatório. A gente vê a importância do esclarecimento da clientela acerca da sua doença, da sua cirurgia, e a gente vê os resultados dessas informações quando o cliente sabe o que ele tem, o que ele pode vir a ter, você vê o nível de ansiedade dele cair. É importante no sentido de complementar a nossa formação, vem a somar. E3

No contexto atual da educação, existe consenso da necessidade de estimular o aluno a aprender através de um processo ensino-aprendizagem dinâmico e mais próximo possível da realidade dos alunos, trabalhar a afetividade, os valores, as percepções dos discentes e docentes, pensando estratégias de ensino inovadoras, e, neste sentido, enfatiza-se a relevância do projeto de extensão desenvolvido nas clínicas de cirurgia geral do HUPE como forma criativa e eficaz de ensinar e aprender.

A partir do modelo de produção neoliberal e da globalização, têm-se vivenciado mudanças socioeconômicas e culturais significativas, que transformam rapidamente as formas de pensar e o comportamento da sociedade. Por sua vez, as inovações tecnológicas, tais como a robótica e a internet, vêm propiciando a difusão do conhecimento, seu compartilhamento entre diversos povos, modificando as relações de ensino-aprendizagem. Diante desse contexto, verifica-se a necessidade de repensar o processo ensino-aprendizagem e as estratégias para o alcance das competências e das habilidades a serem atingidas pelos profissionais. Corroborando esse ponto de vista, Almeida e Souza ${ }^{4}$ asseveram que:

Vive-se atualmente num cenário de mudanças sociais e econômicas que geram um processo acelerado de modernização científica e tecnológica, que acarretam novas formas de construção do conhecimento e de relação com o mundo do trabalho. Assim, torna-se necessário avançar na formação do novo profissional, que, além da qualificação técnico-científica, esteja preparado para aprender, criar, propor, construir, tomar decisões, trabalhar em equipe e enfrentar situações de mudanças ${ }^{4: 205}$.

0 projeto de extensão, enquanto uma estratégia de ensinoaprendizagem, caracteriza-se como uma forma diferente de construção e/ou consolidação do conhecimento dos futuros enfermeiros, mostrando-se dinâmico, unindo a teoria à prática, estimulando os alunos, uma vez que eles podem verificar a aplicabilidade do conhecimento e os resultados positivos dessa aplicabilidade junto ao seu objeto de trabalho - o cuidado a clientes e seus familiares. Referindo-se à importância da atividade de extensão na Universidade do Estado do Rio de Janeiro, Silva 9:191 ressalta que: "os questionamentos devem estimular e provocar reflexões, vislumbrando novos modelos e até, quem sabe, novos paradigmas que possam substituir as ineficazes fórmulas já congeladas".

No processo de aquisição e consolidação do conhecimento, faz-se relevante que sejam oferecidas aos alunos variadas formas ou estratégias para a construção do saber, pois torna o processo mais estimulante, amplia as possibilidades de capacitação e desenvolve nos discentes uma visão mais global e contextualizada. Na visão dos sujeitos da pesquisa, o projeto de extensão mostrou ser mais uma estratégia favorável à capacitação dos futuros enfermeiros.

\section{CONSIDERAÇÕES FINAIS}

0 desenvolvimento dessa pesquisa possibilitou verificar 0 intercâmbio de conhecimento que se estabeleceu entre alunos de períodos diferentes devido às atividades de extensão ocorridas no local de campo de prática. A pesquisa também mostrou que este intercâmbio favoreceu a socialização do conhecimento teóricoprático e as relações afetivas, promoveu sensação de segurança nos alunos e, em última instância, possibilitou diminuir os déficits de conteúdos apresentados pelos grupos envolvidos.

Destaca-se que o grupo de alunos envolvidos na pesquisa adquiriu confiança, pois ficou evidente que é sempre possível trocar experiências e saber apesar de ainda se encontrarem em formação acadêmica. Os laços afetivos foram consolidando-se e, mostrando a possibilidade do trabalho em conjunto, apontando inclusive para a reflexão de possíveis estratégias para a construção de um trabalho em equipe e, quem sabe, interdisciplinar.

0 intercâmbio de conhecimento estabelecido entre acadêmicos e internos de enfermagem propiciado pelo projeto de extensão "Orientando o Cliente em Situação Cirúrgica para Diferenciar o Cuidado" também apontou para a construção de um sentimento de valorização e de segurança para ambas as partes, pois os alunos sentiram-se amparados quando apresentavam dificuldades em realizar alguma atividade, e, por sua vez, o outro que apoiava e ensinava apresentava uma elevação de sua auto-estima.

Considerou-se que a atividade de extensão é uma estratégia eficaz para socializar e difundir conhecimento teórico-prático, estimular o processo de ensinar e de aprender tornando-o mais dinâmico revelando-se inclusive, como uma forma prazerosa e interessante para melhor qualificar os futuros enfermeiros. 


\section{Referências}

1. Universidade Estadual de Londrina (PR). Projeto de Extensão, [on-line] [citado 18 mar 2007]. Disponível em: www.proex.uel.br/ download/proj ext

2. Cianciarullo TI. Instrumentos básicos para o cuidar: um desafio para a qualidade de assistência. São Paulo(SP): Atheneu; 2000.

3. Souza NVO, Silva MF, Marquês GS, Rodrigues FR, Cruz EJER. Avaliando as orientações de enfermagem no período perioperatório segundo perspectivas do cliente cirúrgico. Rev OBJN 2006 jan; 5(1): 01-10.

4. Almeida APS, Souza NVDO. Estudo de caso: uma estratégia para construção de atitude crítico-reflexiva em discentes de enfermagem. Rev. Enferm UERJ. 2005 maio/ago; 13 (2): 204-

5. Lüdke M, André M. A pesquisa em educação: abordagens qualitativas. São Paulo(SP): EPU; 1986.

6. Triviños ANS. Introdução à pesquisa em ciências sociais: a pesquisa qualitativa em educação. São Paulo(SP): Atlas; 1987.

7. Fortes PAC Ética e saúde: questões éticas, deontológicas e legais, tomada de decisão, autonomia e direitos do paciente, estudo de caso. São Paulo(SP): EPU; 1998.

8. Bardin L. Análise de conteúdo. Lisboa(P0): Ed 70; 1995.

9. Silva MTN. A extensão na UERJ: gestão 1996-1999. Rev Enferm UERJ. 1999 jul/dez; 7(2): 189-92.

10. Camacho ACLF, Espírito Santo FH. Refletindo sobre o cuidar e o ensino na enfermagem. Rev. Latino-am Enfermagem 2001 jan; 9(1): 13-7.11. Mostardeiro SCTS Refletindo sobre a formação do enfermeiro: a prática docente a partir do imaginário pedagógico. Escola Anna Nery Rev. Enferm 2004 abr; 8(1): 87-91.

\section{Nota}

a Internos de enfermagem são alunos que estão matriculados nos dois últimos períodos do curso de graduação da Faculdade de Enfermagem da Universidade do Estado do Rio de Janeiro, ou seja, $8^{\circ}$ e $9^{\circ}$ períodos.

\section{Sobre as Autoras}

\section{Norma Valéria Dantas de Oliveira Souza}

Professora Adjunta do Departamento de Enfermagem Médico Cirúrgica da Faculdade de Enfermagem da Universidade do Rio de Janeiro (FE/UERJ).

\section{Maristela Freitas Silva}

Professora Assistente do Departamento de Enfermagem Médico-Cirúrgica da FE/UERJ.

\section{Luciana Ranauro Assumpção}

Aluna do $6^{\circ}$ Período do Curso de Graduação da FE/UERJ.

\section{Keila Suellen Moura Nunes}

Aluna do $5^{\circ}$ Período do Curso de Graduação da FE/UERJ.

\section{Fabiana Maia Morgado}

Aluna do $6^{\circ}$ Período do Curso de Graduação da FE/UERJ. 